\title{
Pengaruh Wiyata Ligkungan Dan Kecerdasan Naturalis Terhadap Sikap Kepedulian Lingkungan Bagi Siswa MI
}

\author{
Agung Purwono', Tsamrotul Jannah ${ }^{2}$ \\ ${ }^{1}$ Institut KH. Abdul Chalim. \\ Email : agungpurwono89@yahoo.com \\ ${ }^{2}$ Institu KH. Abdul Chalim \\ Eemail : tsamrotuljannah54@gmail.com
}

\begin{tabular}{|c|c|}
\hline Kata Kunci & Abstrak \\
\hline $\begin{array}{l}\text { Sikap, Peduli, } \\
\text { Lingkungan }\end{array}$ & $\begin{array}{l}\text { Sikap kepedulian lingkungan sangat diperlukan, karena melihat kondisi sekarang } \\
\text { yang makin banyak kasus kerusakan lingkungan dan bencana alam yang } \\
\text { disebabkan oleh tangan manusia. Penanaman sikap peduli lingkungan sejak dini } \\
\text { sangat diperlukan. Tidak hanya kecerdasan Naturalis yang dimiliki oleh siswa } \\
\text { yang membantu pembentukan sikap peduli lingkungan, penerapan program di } \\
\text { sekolah juga mendukung penanaman sikap peduli lingkungan. Pemerintah juga } \\
\text { sudah berkerja sama antara menteri lingkungan hidup dan menteri pendidikan } \\
\text { untuk penerapan sekolah berbasis adiwwiyata. Namun, tidak semua sekolah } \\
\text { mampu menerapkan program tersebut. Lembaga sekolah MI Dwi Dasa Warsa } \\
\text { juga berusaha menanamkan sikap tersebut kepada siswanya, meskipun lembaga } \\
\text { tersebut tidak berbasis adiwiyata. Tujuan penelitian ini adalah untuk mengetahui } \\
\text { seberapa besar pengaruh dari penerapan program wiyata lingkungan dan } \\
\text { kecerdasan naturalis terhadap sikap peduli lingkunag siswa MI Dwia Dasa Warasa } \\
\text { Trawas Mojokerto. Penelitian ini merupakan penelitian kuantitatif dengan } \\
\text { pendekatan korelasi. Penelitian dilaksanakan di MI Dwi Dasa Warsa. Sampel } \\
\text { dalam penelitian ini berjumlah } 74 \text { siswa dan diambil secara acak. Pengambilan } \\
\text { data pada penelitian ini menggunakan skala linkert, observasi, dokumentasi dan } \\
\text { wawancara. Hasil penelitian ini menunjukkan ada korelasi antara penerapan } \\
\text { program wiyata lingkungan dengan sikap peduli lingkungan (p=0,00). Sedangkan } \\
\text { korelasi antara kecerdasan naturalis dengan sikap kepedulian lingkunga siswa } \\
\text { (p=0,00). Dapat disimpulkan bahwa terdapat hubungan yang positif dari } \\
\text { penerapan program wiyata lingkungan dan kecerdasana naturalis dengan sikap } \\
\text { peduli lingkungan. }\end{array}$ \\
\hline Keywords: & Abstract \\
\hline $\begin{array}{l}\text { Attitude, Care, } \\
\text { Environment }\end{array}$ & $\begin{array}{l}\text { Caring for the environment is very necessary because it sees the current condition } \\
\text { that more and more cases of environmental damage and natural disasters caused } \\
\text { by human hands. Planting an attitude of caring for the environment from an early } \\
\text { age is very necessary. It is not only ecological intelligence possessed by students } \\
\text { that helps shape the attitude of caring for the environment. The implementation of } \\
\text { the program in schools also supports the cultivation of attitudes to care for the } \\
\text { environment. The government has also collaborated with the environment minister } \\
\text { and the minister of education. For the application of adiwwiyata-based schools. } \\
\text { But not all schools are able to implement the program. The MI Dwi Dasa Warsa } \\
\text { school institution also tried to instill this attitude in its students even though the } \\
\text { institution was not based on adiwiyata. The purpose of this study is to find out } \\
\text { how much influence the application of the environment environment program and } \\
\text { naturalical intelligence on the attitude of environmental care students of MI Dwia } \\
\text { Dasa Warasa Trawas Mojokerto. These research are kuantitative with } \\
\text { correlation's descriptive to } 74 \text { student. The results of this study indicate the } \\
\text { correlation of the application of the wiyata environmental program with an } \\
\text { attitude of environmental care (p=000). and there is correlation between naturalist } \\
\text { intelligence with environmental awareness attitude of students is (p=0.00). It can }\end{array}$ \\
\hline
\end{tabular}


be concluded that there is a positive relationship between the application of the environment realy program and naturalical intelligence with an attitude of caring for the environment.

Submission: April 4, 2020. Revised: June 26, 2020. Accepted: June 30, 2020

\section{A. Pendahuluan}

Melihat dari kenyataan pada era sekarang, masalah lingkungan yang semakin bertambah. Seperti pencemaran sungai, kerusakan hutan, tanah longsor, banjir, abrasi, pencemaran udara, menurunnya keaneka ragaman hayati, pencemaran tanah, permasalahan sampah yang menumpuk dan pemanasan global serta berkurangnya daerah resapan air (Harahap, 2015). Peran pemerintah dalam memecahkan persoalan lingkungan melalui jalur pendidikan dengan membuat kesepakatan antar Menteri Pendidikan Nasional dan Menteri Lingkungan Hidup tentang sekolah berbudaya lingkungan (Desfandi, 2015).

Permasalah lingkungan yang paling dekat dengan kehidupan peserta didik yaitu masalah sampah dan pencemaran udara. Semua itu disebabkan kurangnya kepedulian masyarakat terhadap lingkungan di sekitarnya (Rusdina, 2015). Oleh karena itu, dianjurkan bagi lembaga pendidikan untuk menerapkan sekolah berbasis adiwiyata. Lingkungan sekolah adalah salah satu tempat yang kondusif untuk kegiatan belajar mengajar. Lingkungan sekolah juga dapat menjadi tempat pendidikan karakter bagi peserta didik .

Pendidikan karakter kepedulian lingkungan hidup adalah program pendidikan untuk membina peserta didik supaya mempunyai kepekaan, kesadaran diri, sikap, dan perilaku yang mencerminkan rasa tanggung jawab terhadap lingkungannya (Hakim \& Rahayu, 2019). Kecerdasan ekologis adalah kemampuan untuk beradaptasi terhadap ruang ekologis tempat kita berada (Daniel Goelman, 2010). Gardner 92013) menyebut kecerdasan ekologis dengan istilah kecerdasan naturalis. Menurutnya, kecerdasan naturalis adalah kemampuan manusia dalam memahami gejala-gejala alam, memperlihatkan kesadaran dan menunjukkan kepekaan manusia terhadap alam. Kecerdasan naturalis yang dimiliki peserta didik juga dibutuhkan dalam mengatasi permasalah lingkungan yang ada, agar peserta didik dapat lebih cerdas dalam melihat dampak ekologis yang ditimbulkan dari setiap aktivitas yang dilakukanya. Kecerdasan natulais yang dimaksudkan dalam penelitian ini adalah kepekaan dan munculnya rasa tanggung jawab terhadap perubahan yang ada pada lingkungan alam sekitar mereka baik di sekolah maupun di rumah. Menurut Palmer \& Neal komponen kecerdasan ekologi dalam proses pendidikan di lembaga sekolah adalah dengan mengembangkan rasa kepekaan, kesadaran lingkungan dan pemikiran kritis serta keterampilan pemecahan masalah dalam permsalahan lingkungan serta pembentukan etika peduli lingkungan hidup (Deswari, 2015).

Kecerdasan ekologi dapat memahamkan kita akan dampak dari prilaku manusia terhadap ekosistem lingkungan sekitarnya, sehingga kerusakan alam dapat terhindarkan. Melihat ancaman pada dewasa ini menuntut kita untuk lebih peka terhadap semua dampak dari perbuatan manusia agar dapat mengurangi kerusakan alam. Goleman berpendapat bahwa istilah kecerdasan ekologi yang digunakan sekarang ini meliputi kemampuan naturalis asli untuk mengategorikan beberapa ilmu sains yang termasuk di dalamnya, menerapkan pandangan ilmu tersebut pada sistem yang selalu berubah saat beroprasi dalam skala apapun. Pengetahuan yang mengenai semua cara kerja sesuatu dan alam tersebut serta cara mengetahui dan memahami interaksi antara pola yang dibuat manusia dan pola yang terbentuk di alam.

Melihat kondisi lingkungan sekolah MI Dwi Dasa Warsa yang berdampingan dengan perhutanan, pegunungan, tempat wisata alam, jalan raya, komplek villa, dan perhotelan, merupakan tantangan pihak sekolah dalam rangka terwujudnya lingkungan yang sekolah yang 
hijau, sehat dan asri. Melihat kondisi sekolah MI Dwi Dasa Warsa tersebut, pihak sekolah memiliki kewajiban untuk membentuk karakter peserta didiknya untuk mencintai lingkungannya sejak dini, oleh sebab itu pihak sekolah melaksanakan program wiyata lingkungan guna melatih kecerdasan Naturalis dan sikap peduli lingkungan peserta didik serta warga sekolah yang lainnya. Namun, lembaga ini tidak menerapkan sekolah berbasis adiwiyata yang dianjurkan oleh pemerintah, hanya saja lembaga ini menerapkan program wiyata lingkungan yang dilaksanakan setiap pagi sebelum masuk kelas. Kecerdasan/inteligensi atau dalam bahasa latinnya adalah "intelligence" yang berarti penghubungan atau penyatuaan satu sama lain (to organize, to relate, to bind together) (Wardiana, 2004).

Banyak penafsiran kata inteligensi dari ahli atau peneliti. Edward Lee Thorndike, seorang psikolog asal Amerika serikat berpendapat bahwa kecerdasan dibagi menjadi tiga yaitu kecerdasan riil, kecerdasan abstrak dan kecerdasan sosial (Prawira, 2012). Namun pada saat ini, teori kecerdasan yang menjadi induk bagi teori kecerdasan yang berkembang adalah teori Howard Gagner yang dikenal dengan Multiple Intelligence (Amir, 2013). Kecerdasan tersebut dibagi menjadi sembilan kategori, yaitu: Linguistic Intelligence (Kecerdasan Linguistik), yaitu kemampuan manusia dalam hal kebahasaan atau berkomunikasi,baik melalui bahasa tulis maupun lisan; Mathematic logic (Kecerdasan matematis logis), yaitu kecerdasan dalam hal berhitung secara matematis dan logika efektif; Kecerdasan ruang, yaitu kecerdasan dalam hal menggambarkan ruang baik secara lisan maupun tulis serta dengan mudah memahami grafik;

Kinestetic Intelligence (Kecerdasan kinestetik), yaitu kecerdasan dalam hal memanfaatkan potensi fisik; Musical Intelligence (Kecerdasan musikal), kemampuan yang lebih dalam hal praktik musikal atau pemahaman musik, nada, rama, ritme dan bunyi-bunyian atau nyanyian; Interpersonal Intelligence (Kecerdasan interpersonal), kemampuan yang lebih dalam hal pemahaman perasaan orang lain atau kepekaan terhadap reaksi lingkungan sekitar;

Intrapersonal Intelligence (Kecerdasan intrapersonal), kemampuan untuk memahami diri dan perasaan hatinya yang sangat tinggi; Natural Intelligence (Kecerdasan natural), yaitu kemampuan manusia dalam memahami alam sekitar atau memiliki kepekaan yang tinggi terhadap alam. Kecerdasan Eksistensial, yaitu kemampuan manusia dalam menjawab persoalan eksistensinya sebagai manusia sosial. Sembilan kecerdasan tersebut di atas, saat ini sudah mulai bahkan banyak diterapkan dan dikembangkan di lembaga-lembaga sekolah.

Kecerdasan Naturalis yaitu kemampuan manusia dalam memahami alam sekitar atau memiliki kepekaan yang tinggi terhadap alam (Gardner, 2013. Kecerdasan Nanturalis yaitu keahlian dalam mengenali dan mengklasifikasi berbagai spesies flora dan fauna (Armstrong, 2009). Sedangkan menurut siantayani (2011) menyatakan bahwa kecerdasan naturalis yaitu kecerdasan yang melibatkan kemampuan mengenal bentuk-bentuk alam sekitar, bunga, pohon, alam sekitar dan juga binatang-binatang. Hal ini berarti kecerdasan naturalis memiliki hubungan yang sangat erat dengan segala sesuatu di lingkungan sekitar. Dengan demikian maka dapat disimpulkan bahwa kecerdasan naturalis yaitu kemampuan mengenali membedakan dan membuat kategori yang berhubungan dengan flora ataupun fauna serta benda-benda alam yang ada di lingkungan sekitar (Robbiyah dkk, 2018). Menurut pendapat Hines ada 4 inti yang harus ada dalam kecerdasan naturalis (Muhaimin, 2015), yaitu: Kepekaan dan kefahaman isu-isu lingkungan, Terampil dalam menyikapi isu-isu yang muncul di lingkungan, Keterampilan dalam hal bertindak Ketdan erampilan dalam hal personalitas yang baik.

Lingkungan adalah kombinasi antara biotik dan abiotik yang ada di atas dan di dalam permukaan bumi yang mencakup juga di dalamnya adalah kelembagaan sebagai wujud ciptaan manusia seperti adanya keputusan penggunaan sumberdaya alam secara fisik (Wahyudi \& Aisah, 2018). Menurut Otto (1994) lingkungan hidup adalah suatu ruang yang ditempati oleh 
Agung Purwono, Tsamrotul Jannah

Pengaruh Wiyata Ligkungan Dan Kecerdasan Naturalis Terhadap Sikap Kepedulian

Linakunaan Baai Siswa MI

makhluk hidup bersama dengan benda-benda di sekelilingnya, baik yang hidup maupun tak hidup. Bisa juga dipahami sebagai semua benda, kondisi dan semua hal yang berpengaruh terhadap lingkungan kita termasuk kehidupan manusia, atau juga bisa dipahami lingkungan hidup merupakan seluruh benda hidup dan tidak hidup yang ada di alam sekitar (Kahfi, 2014). Salah satu penelitian yang pernah dilakukan terkait lingkungan adalah Pengaruh pendekatan saintifik terhadap keterampilan berpikir kritis siswa subtema keberagaman makhluk hidup di lingkunganku kelas IV sekolah dasar dengan hasil bahwa pendekatan saintifik memberikan pengaruh terhadap keterampilan berpikir kritis siswa (Agustin, 2019). Berdasarkan penjelasan tersebut dapat diklasifikasikan bahwa lingkungan terdiri dari komponen biotik dan abiotik.

\section{B. Metodologi}

Penilitian ini menggunakan pendekatan kuantitatif. Penelitian Kuantitatif yaitu sebuah penelitian yang menggunakan landasan positivisme, yang digunakan dengan tujuan meniliti sampel atau populasi tertentu, pengumpulan datanya dengan menggunakan intrumen penelitian, analisis data bersifat kuantitatif/ statistik yang bertujuan untuk menguji hipotesis yang telah ditetapkan (Sugiyono, 2016). Populasi dalam Penelitian ini adalah semua siswa MI Dwi Dasa Warsa mulai siswa kelas 1-6 yang berjumlah 278 siswa, 133 siswa laki-laki dan 145 siswa perempuan, dengan kisaran usia antara 7-12 tahun. Dengan menggunakan teknik random sampling didapatkan sampel sebesar 74 orang.

Penelitian terdiri dari 3 variabel yakni 2 variabel bebas dan 1 variabel terikat. Adapun variabel bebas dalam penelitian ini yakni penerapan program wiyata lingkungan dan kecerdasan naturalis. Sedangkan variabel terikatnya yaitu sikap peduli lingkungan. Interview, pengumpulan data, dokumentasi dan observasi digunaakan sebagai metode pengambilan data pada penelitian ini. Data dianalisis menggunakan analisis korelasi, analisis korelasi berganda, uji parsial (t-test), analisi liner berganda.

\section{Hasil Dan Pembahasan}

\section{Hasil Uji Validitas dan Reabilitas}

\section{Hasil Uji Validitas Program Wiyata Lingkungan}

Hasil uji validitas pada variabel program wiyata lingkungan menunjukkan bahwa terdapat 3 item pertanyaan dari 18 item pertanyaan, yang memiliki nilai rxy hitungnya lebih kecil dari nilai rxy tabel untuk $\mathrm{n}=25$ dan $\alpha=5 \%(0,396)$. Jumlah item yang valid dan digunakan dalam penelitian adalah 15 item pertanyaan. Item yang gugur pada variabel program wiyata lingkungan yaitu, item 3, 5, dan 8 . Keterangan terdapat pada tabel validitas.

\section{Hasil Uji Validitas Kecerdasan Naturalis}

Hasil uji validitas dari variabel kecerdasan naturalis menunjukkan bahwa terdapat 3 item pertanyaan dari 18 item pertanyaan, yang memiliki nilai $r_{x y}$ hitungnya lebih kecil dari $r_{x y}$ tabel untuk $n=25$ dan $\alpha=5 \%(0,396)$. Jumlah item yang valid dan di gunakan untuk penelitian adalah 15 item pertanyaan. Item yang gugur pada variabel kecerdasan ekologis siswa yaitu, item 1, 7, dan 9. Keterangan terdapat pada tabel validitas.

\section{Hasil Uji Validitas Sikap Peduli Lingkungan}

Hasil uji validitas variabel sikap peduli lingkungan diatas terdapat 3 ietem pertanyaan dari 20 item pertanyaan, yang mempunyai nilai $r_{\mathrm{xy}}$ hitung lebih kecil dari $\mathrm{r}_{\mathrm{xy}}$ tabel untuk $\mathrm{n}=25$ dan $\alpha=5 \%(0,396)$. Jumlah item yang valid dan di gunakan untuk penelitian adalah 17 item 
petanyaan. Item yang gugur pada variabel sikap peduli lingkungan yaitu item pertanyaan nomor 6, 20, dan 18. Keterangan terdapat di tabel validitas.

\section{Hasil Uji Reabilitas}

Tabel 1. hasil uji reabilitas

\begin{tabular}{|l|l|l|}
\hline Variabel & $\mathrm{r}_{11}$ & Interpretasi \\
\hline Program wiyata lingkungan & 0,798 & Cukup \\
\hline Kecerdasan naturalis & 0,856 & Tinggi \\
\hline Sikap peduli lingkungan & 0,890 & Tinggi \\
\hline
\end{tabular}

Hasil uji reabilitas dari semua variabel penelitian adalah Hasil uji reabilitas dari variabel program wiyata lingkungan terdapat pada tabel 1yang menunjukkan nilai 0,798, variabel kecerdasan naturalis sebesar 0,856, dan sikap peduli lingkungan sebesar 0,890. Satu variabel penelitian yang mempunyai nilai reabilitas kategori cukup, dan dua variabel penelitian yang mempunyai nilai reabilitas tinggi.

\section{Pengaruh Program Wiyata Lingkungan terhadap Sikap Kepeduian Lingkungan}

Tabel 2. Hasil Uji Korelasi antara Program Wiyata Lingkungan terhadap Sikap Kepeduian Lingkungan

\begin{tabular}{|ll|r|r|}
\hline & & $\begin{array}{c}\text { Program Wiyata } \\
\text { Lingkungan }\end{array}$ & \multicolumn{2}{c|}{$\begin{array}{c}\text { Sikap Peduli } \\
\text { Lingkungan }\end{array}$} \\
\hline Program wiyata lingkungan & Pearson correlation & 1 & .831 \\
& Sig. (2-tailed) & 74 & $.000^{*}$ \\
& $\mathrm{~N}$ & 74 \\
\hline Sikap peduli lingkungan & Pearson correlation & .831 & 1 \\
& Sig. (2-tiled) & $.000^{*}$ & 74 \\
& $\mathrm{~N}$ & 74 & 74 \\
\hline
\end{tabular}

*Uji Korelasi menggunakan Pearson menunjukkan signifikan

Melihat hasil uotput SPSS terdapat pengaruh yang signifikan antara program wiyata lingkungan terhadap sikap peduli lingkungan $(\mathrm{p}=0,00)$.

Tabel 3. hasil uji regresi sederhana SPSS

\begin{tabular}{|l|c|c|c|c|}
\hline Model & $\mathrm{R}$ & R Squere & $\begin{array}{c}\text { Adjusted R } \\
\text { Squere }\end{array}$ & $\begin{array}{c}\text { Std. Error of } \\
\text { The Estimate }\end{array}$ \\
\hline 1 & $.831^{a}$ & .691 & .687 & 3.719 \\
\hline
\end{tabular}

Hasil output SPSS di atas menunjukkan nilai R Square atau koefisien determinasi (KD) yang menunjukkan seberapa bagus model regresi yang dibentuk oleh interaksi variabel program wiyata lingkungan dengan sikap peduli lingkungan. Nilai $R$ square yang diperoleh 0,691 atau $69,1 \%$ yang dapat ditafsirkan bahwa variabel program wiyata lingkungan memiliki pengaruh sebesar $69,1 \%$ terhadap sikap peduli lingkungan siswa MI Dwi Dasa Warsa dan 30.9\% dipengaruhi oleh faktor lain diluar variabel program wiyata lingkungan. MI Dwi Dasa Warsa Trawas merupakan salah satu lembaga pendidikan tingkat dasar di kabupaten Mojokerto. MI Dwi Dasa Warsa terletak di jalan Ki Ageng Tambak Boyo, desa Ketapanrame, Kecamatan Trawas, Kabupaten Mojokerto. Madrasah ini didirikan atas prakarsa tiga pihak yaitu: masyarakat, para ulama, dan pemerintah.

Madrasah ini didirikan pada tahun 1965. Tepat 20 tahun setelah kemerdekaan Indonesia. Untuk mengenang sejarah tersebut madrasah ini diberi nama Dwi Dasa Warsa yang memiliki arti 20 tahun setelah Indonesia merdeka. MI Dwi Dasa Warsa memiliki visi "Membentuk insan 
yang bertaqwa, cerdas, terampil dan berakhlakul karimah. Madrasah ini memiliki siswa sebanyak 278 siswa, guru dan karyawan sebanyak 17 orang.

Hasil penelitian ini menunjukkan bahwa ada pengaruh yang posistif antara penerapan program wiyata lingkungan terhadap sikap peduli lingkungan siswa MI Dwi Dasa Warsa Ketapanrame Trawas Mojokerto. Penerapan program wiyata lingkungan ini membantu pembentukan karakter sikap peduli lingkungan siswa. Hasil penelitian menunjukkan bahwa kesadaran terhadap program yang sudah dibentuk oleh pihak sekolah yaitu wiyata lingkungan menunjukkan nilai yang tingi. Memiliki korelasi atau hubungan sebesar 0,831 atau 83,1\% dan itu menunjukkakn kategori sangat kuat. Sedangkan penelitian yang sudah pernah dilaksankan menunjukkan hubungan yang positif namun penelitian terdahulu dilakasanakan di lembaga yang sudah berbasis adiwiyata.

Penerapan program yang sudah diterapkan oleh pihak sekolah sejak tahun 2013 dan sangat membantu pembentukan karakter sikap peduli lingkungan siswa. Sikap peduli lingkungan sangat dibutuhkan oleh generasi milenial, agar memiliki kesadaran akan pelestarian sumber daya alam yang ada. Meminimalkan kerusakan lingkungan juga membutuhkan kepekaan terhadap lingkungan sekitarnya. Melihat lingkungan di sekitar MI Dwi Dasa Warsa yang sangat membutuhkan generasi-generasi milinial yang peka akan kondisi alam.

\section{Pengaruh Kecerdasan Naturalis Siswa terhadap Sikap Peduli Lingkungan}

Tabel 4. Hasil Uji Korelasi antara Kecerdasan Naturalis dengan terhadap Kepeduian Lingkungan

\begin{tabular}{|ll|r|r|}
\hline & & $\begin{array}{c}\text { Kecerdasan } \\
\text { naturalis }\end{array}$ & \multicolumn{2}{c|}{$\begin{array}{c}\text { Sikap peduli } \\
\text { lingkungan }\end{array}$} \\
\hline Kecerdasan ekologis & Pearson Correlation & 1 & .855 \\
& Sig. (2-tiled) & 74 & $.000^{*}$ \\
& $\mathrm{~N}$ & .855 & 74 \\
\hline Sikap peduli lingkungan & Pearson Correlation & $.000^{*}$ & 1 \\
& Sig. (2-tiled) & 74 & 74 \\
& $\mathrm{~N}$ & & 74 \\
\hline
\end{tabular}

*Uji Korelasi menggunakan Pearson menunjukkan signifikan

Berdasarkan tabel 4 dapat dilihat bahwa terdapat hubungan yang signifikan antara kecerdasan dengan sikap peduli lingkungan $(\mathrm{p}=0,00)$.

Tabel 5. hasil uji regresi sederhana SPSS

\begin{tabular}{|c|c|c|c|c|}
\hline Model & $\mathrm{R}$ & R Squere & $\begin{array}{c}\text { Adjusted R } \\
\text { Squere }\end{array}$ & $\begin{array}{c}\text { Std. Error of } \\
\text { The Estimate }\end{array}$ \\
\hline 1 & $.855^{\mathrm{a}}$ & .731 & .727 & 3.469 \\
\hline
\end{tabular}

Hasil output SPSS di atas menunjukkan nilai R square yang diperoleh 0,731 atau $73,1 \%$ yang dapat ditafsirkan bahwa variabel kecerdasan naturalis memiliki pengaruh sebesar $73,1 \%$ terhadap sikap peduli lingkungan siswa MI Dwi Dasa Warsa dan 26,9\% dipengaruhi oleh faktor lain diluar variabel kecerdasan naturalis. Hasil penelitian ini menunjukkan bahwa ada pengaruh yang positif antara kecerdasan naturalis yang dimiliki siswa dengan sikap peduli lingkungan. Dalam penelitian yang sudah pernah dilaksankan menunjukkan perkembangan kecerdasan naturalis yang signifikan, namun penelitian tersebut di laksankan di lembaga yang berbasis adiwiyata. Sedangkan, dalam penelitian ini kecerdasan naturalis yang dimiliki siswa mampu membuat siswa sangat peka dengan kondisi lingkungannya. Kondisi lingkungan yang semakin lama semakin banyak masalah dikarenkan ulah tangan manusia ini membutuhkan generasi yang cerdas akan mengolah dan menjaga lingkungannya. 
Melihat hasil penelitian dari tingkat kecerdasan ekologis yang dimiliki siswa tinggi. Memiliki korelasi atau hubungan sebesar 0,855 atau 85,5\% dan itu menunjukkakn kategori sangat kuat. Memiliki kemungkinan sikap kepedulan terhadap lingkungan sekitarnya juga akan tinggi. Memiliki kepekaan terhadap lingkungan sekitarnya itu juga membutuhkan kecerdasan naturalis yang tinggi.

\section{Pengaruh Penerapan Program Wiyata Lingkungan dan Kecerdasan Naturalis terhadap Sikap Peduli Lingkungan.}

Tabel 6. Hasil uji regresi ganda SPSS

\begin{tabular}{|c|c|r|r|r|}
\hline Model & R & R Square & $\begin{array}{c}\text { Adjusted R } \\
\text { Square }\end{array}$ & $\begin{array}{c}\text { Std. Error of } \\
\text { The Estimate }\end{array}$ \\
\hline 1 & $.914^{\mathrm{a}}$ & .835 & .830 & 2.738 \\
\hline
\end{tabular}

Prodictors: (constant), kecerdasan naturalis, program wiyata lingkungan

Hasil output SPSS di atas menunjukkan nilai R yang merupakan simbol dari koefesien. Dapat dilihat diatas memiliki nilai korelasi 0,914 nilai ini dapat diinterpretasikan bahwa hubungan antara program wiyata lingkungan dan kecerdasan naturalis dengan sikap peduli lingkkungan siswa ada dikategori sangat kuat. Melalui tabel ini juga dapat diperoleh nilai $\mathrm{R}$ Square atau koefisien determinasi (KD) yang menunjukkan seberapa bagus model regresi yang dibentuk oleh interaksi variabel program wiyata lingkungan dan kecerdasan naturalis dengan sikap peduli lingkungan. Nilai R square yang diperoleh 0,835 atau $83,5 \%$ yang dapat ditafsirkan bahwa variabel program wiyata lingkungan dan kecerdasan naturalis memiliki pengaruh sebesar 83,5\% terhadap sikap peduli lingkungan siswa MI Dwi Dasa Warsa dan 16,5\% dipengaruhi oleh faktor lain diluar variabel program wiyata lingkungan dan kecerdasan naturalis.

Penelitian yang sudah pernah dilaksankan menunjukkan hubungan yang positif namun penelitian terdahulu dilakasanakan di lembaga yang sudah berbasis adiwiyata. Namun lembaga ini hanya menerapkan program wiyata lingkungan yang yang memiliki dampak yang posistif. Lembaga MI Dwi Dasa Warsa menerapkan program wiyata lingkungan dengan latar belakang agar seluruh siswa dapat mengenal lingkungan di sekitar sekolah dan mampu menjaga lingkungan tersebut. Penelitian ini juga memiliki tujuan untuk meningkatkan kepedulian lingkungan yang dimiliki siswa agar dapat membantu pelestarian lingkungan sekitar sekolah dan lingkungan rumahnya.

Penerapan program wiyata lingkungan ini para tenaga pendidik berperan aktif dalam pendampingan disaat para siswa melaksanakan wiyata lingkungan. Kendala yang dialami saat pelaksanaan program wiyata lingkungan tersebut hanya terkendala waktu pelaksanaanya. Waktu pelaksanaan yang dilakukan setiap pagi sebelum masuk kelas, maka masih banyak siswa yang telat dalam pelaksanaan tersebut. Pihak lembaga juga membuat program LISA (Lihat Sampah Ambil)dengan harapan siswa akan terbiasa menjaga kebersihan dan tidak membuang sampah disembarang tempat.

Melihat lokasi lembaga yang dekat dengan wisata alam dan pegunungan. Para tenaga pendidik juga sudah mulai mengajarkan kepada siswa untuk memilah sampah dengan ttujuan membiasakan siswa untuk mencintai lingkungannya, karena sampah yang tidak dapat diurai dapat merusak lingkungan. Para tenaga pendidik berharap agar siswanya setelah selesai menempuh pendidikan dilembaga tersebut tetap memiliki kepekaan terhadapa lingkungan sekitarnya. 
Agung Purwono, Tsamrotul Jannah

Pengaruh Wiyata Ligkungan Dan Kecerdasan Naturalis Terhadap Sikap Kepedulian

Linakunaan Baai Siswa MI

\section{Kesimpulan}

Berdasarkan hasil penelitian di atas dapat diambil kesimpulan terdapat pengaruh yang positif dan signifikan antara penerapan program wiyata lingkungan dengan sikap kepedulian lingkungan siswa MI Dwi Dasas Warsa dan terdapat pengaruh yang positif dan signifikan antara kecerdasan naturalis yang dimiliki siswa dengan sikap kepedulian lingkungan siswa MI Dwi Dasa Warsa serta terdapat pengaruh yang positif dan signifikan antara penederapan program wiyata lingkungan dan kecerdasan naturalis dengan sikap kepedulian lingkungan siswa MI Dwi Dasa Warsa.

\section{Daftar Pustaka}

Agustin, N. 2019. Pengaruh Pendekatan Saintifik tehadap Keterampilan Berpikir Kritis Siswa Subtema Keberagaman Makhluk Hidup di Lingkunganku Kelas IV Sekolah Dasar. Child Education Journal, 1(1) 36-43. https://doi.org/10.33086/cej.v1i1.912

Amir, A. (2013). Pembelajaran Matematika Dengan Menggunakan Kecerdasan Majemuk (Multiple Intelligences). Logaritma, I(01), 1-14. https://doi.org/10.1111/jofi.12406

Armstrong, T. (2002). Setiap Anak Cerdas: Panduan Anak Belajar dengan Memanfaatkan Multiple Intelegencenya, (alih bahasa: Bantara R). Jakarta: PT Gramedia Pustaka Uatama.

Desfandi, M. (2015). Mewujudkan Masyarakat Berkarakter Peduli Lingkungan Melalui Program Adiwiyata. Social Science Education Journal, 2(1), 31-37. https://doi.org/10.15408/sd.v2i1.1661

Deswari, N. (2015). Membangun Imajinasi dan Kreativitas Anak Melalui Literasi. Membangun Imajinasi dan Kreativitas Anak Melalui Literasi. Prosiding Seminar Nasional Pendidikan Dasar SPS UPI 2015

Gadner, H. 2013. Multiple Intelegence. Jakarta: Daras Books

Hakim, M. N., \& Rahayu, F. D. (2019). Pembelajaran Saintifik Berbasis Pengembangan Karakter. Jurnal Pendidikan Islam, 2(1), 1-27. https://doi.org/10.31538/nzh.v2i1.148

Harahap, R. Z. (2015). Etika Islam dalam Mengelola Lingkungan Hidup. Jurnal EduTech, 1(1), 1-13. Retrieved from www.agamadanekologi.blogspot.com,

Kahfi, A. (2014). Kejahatan Lingkungan Hidup. Al-Daulah, 3(2), 206. https://doi.org/10.1016/S0016-5085(12)60771-9

Muhaimin. 2015. Membangun Kecerdasan Ekologis. Bandung : Alfabeta.

Otto, S. (1994). Ekologi: Lingkungan Hidup dan Pembangunan. Bandung: Djambatan

Prawira, P. A. 2012. Psikologi Pendidikan Dalam Perspektif Baru. Yogayakarta: Arruz Media

Rahayu, G. D. S., \& Setiyadi, R. (2018). Penerapan Model Project Citizen dalam Upaya Meningkatkan Kecerdasan Ekologis. Mimbar Sekolah Dasar, 5(1), 31. https://doi.org/10.17509/mimbar-sd.v5i1.9684

Robbiyah, R., Ekasari, D., \& Witarsa, R. (2018). Pengaruh Pola Asuh Ibu terhadap Kecerdasan Sosial Anak Usia Dini di TK Kenanga Kabupaten Bandung Barat. Jurnal Obsesi : Jurnal Pendidikan Anak Usia Dini, 2(1), 74. https://doi.org/10.31004/obsesi.v2i1.10

Rusdina, A. (2015). Membumikan Etika Lingkungan Bagi Upaya Membudayakan Pengelolaan 
Lingkungan yang Bertanggung Jawab. Istek, 9(2), 244-263.

Santoso, S. 2010. Statistik Parametrik, konsep dan aplikasi dengan SPSS. Jakarta: PT Gramedia.

Siantiyani, Y. (2011). Persiapan Membaca Bagi Balita. Sleman Yogyakarta: Kritzer Publisher. https://ejournal.uksw.edu/satyawidya/article/view/1567

Wahyudi, D., \& Aisah, S. (2018). Aktualisasi Pendidikan Islam Dalam Pengelolaan Lingkungan Hidup: Studi Relasi Antara Pendidikan Islam dan Budaya Mistis Dalam Pelestarian Lingkungan. Tarbawiyah Jurnal Ilmiah Pendidikan, 2(01), 124. https://doi.org/10.32332/tarbawiyah.v15i01.1200

Wardiana, Uswah. 2004. Psikologi Umum. Jakarta: PT. Bina Ilmu 